\title{
Analysis of the US Food and Drug Administration Manufacturer and User Facility Device Experience database for adverse events involving Amplatzer septal occluder devices and comparison with the Society of Thoracic Surgery congenital cardiac surgery database
}

Daniel J. DiBardino, MD, ${ }^{\mathrm{a}}$ Doff B. McElhinney, MD, ${ }^{\mathrm{b}}$ Aditya K. Kaza, MD, ${ }^{\mathrm{a}}$ and John E. Mayer, Jr, MD ${ }^{\mathrm{a}}$

Objective: Amplatzer (AGA Medical Corporation, Plymouth, Minn) septal and vascular occluder devices have significantly altered the care of patients with congenital heart disease. The relative frequency and consequence of complications resulting from the attempted placement of such devices, however, have not been well assessed. The purpose of this study is to use large databases to assess the frequency and severity of such complications and compare them with those of surgical atrial septal defect closure.

\begin{abstract}
Methods: The US Food and Drug Administration Manufacturer and User Facility Device Experience database was quarried for all adverse events for Amplatzer septal occluder devices, which were categorized and analyzed with particular emphasis on management and outcome. The Society of Thoracic Surgery database was likewise quarried for the same data regarding atrial septal defect closures over a contemporaneous time period. By using a literature-derived denominator for total Amplatzer implant numbers, the results of the 2 therapies were compared.
\end{abstract}

Results: Since July 1, 2002, 223 adverse events in patients undergoing Amplatzer atrial septal defect closure were submitted to the Food and Drug Administration, resulting in 17 deaths (7.6\%) and 152 surgical rescue operations $(68.2 \%)$. Society of Thoracic Surgery data demonstrated 1537 primary operations with 2 deaths $(0.13 \%)$ and 6 reoperations $(0.39 \%)$. By extrapolating on published estimates of Amplatzer implantation to provide an implant denominator $(\mathrm{n}=18,333)$, there was no difference between overall mortality for surgical $(0.13 \%)$ and device closure $(0.093 \%, P=.649)$. Rescue operation for device adverse events $(0.83 \%)$ was 2.1 times more likely than reoperation for surgical closure $(0.39 \%, P=.063)$. Mortality per adverse event was higher for device closure $(7.6 \%)$ than for surgical closure $(1.2 \%, P=.004)$, and the need for surgery per adverse event was higher for device closure $(68.2 \%)$ than for surgical closure $(3.6 \%, P<.001)$. The mortality for surgical management of a device adverse event $(2.6 \%)$ was 20 -fold higher than for primary elective atrial septal defect closure $(0.13 \%, P<.0001)$.

Conclusion: Overall crude mortality for device and surgical closure atrial septal defect closure is equivalent, and the need for subsequent operation (surgical rescue) is more common in patients undergoing device closure than reoperation is in patients undergoing surgical closure. Complications from device closure tend to be serious and most often require urgent or emergency operative management, whereas the mortality for surgical management of a device complication appears higher than that of elective atrial septal defect closure. Further information is required in the form of postmarketing surveillance, such as a mandatory user registry with periodic end-user notification.

Earn CME credits at

http://cme.ctsnetjournals.org

\footnotetext{
From the Departments of Cardiac Surgery ${ }^{\mathrm{a}}$ and Cardiology, ${ }^{\mathrm{b}}$ Children's Hospital Boston, Harvard Medical School, Boston, Mass.

Read at the Eighty-eighth Annual Meeting of the American Association for Thoracic Surgeons, May 11-14, 2008, San Diego, California.

Received for publication May 25, 2008; revisions received Dec 26, 2008; accepted for publication Feb 16, 2009

Address for reprints: Daniel J. DiBardino, MD, Cardiac Surgery, Children's Hospital Boston, 300 Longwood Avenue, Boston, MA 02215 (E-mail: ddibardino@partners. org).

J Thorac Cardiovasc Surg 2009; 137:1334-41

$0022-5223 / \$ 36.00$

Copyright (c) 2009 by The American Association for Thoracic Surgery

doi:10.1016/j.jtcvs.2009.02.032
}

Amplatzer septal and vascular occluder devices (Amplatzer, AGA Medical Corporation, Plymouth, Minn) have significantly altered the care of patients with congenital heart disease and are becoming standard care in many institutions. The relative frequency, consequence, and cost of complications resulting from the attempted placement of the Amplatzer occluder devices, however, have not been well assessed. The overall mortality and need for surgical intervention are unknown. In addition, periprocedural adverse events (AEs) for catheter therapies often mandate operative intervention such that an analysis of the patterns of such failures are germane to the cardiac surgeon and essential to the cardiologist providing informed consent to patients and families. To generate such data, an analysis was undertaken of the US Food and Drug Administration (USFDA) on-line database for devicerelated AEs, and a denominator of device implants was 

Abbreviations and Acronyms

$\begin{aligned} \mathrm{AE} & =\text { adverse event } \\ \mathrm{ASD} & =\text { atrial septal defect } \\ \mathrm{MAUDE}= & \text { Manufacturer and User Facility } \\ & \text { Device Experience } \\ \mathrm{PER}= & \text { perforation/erosion/rupture } \\ \mathrm{PFO}= & \text { patent foramen ovale } \\ \mathrm{STS} & =\text { Society of Thoracic Surgery } \\ \mathrm{USFDA}= & \text { US Food and Drug Administration }\end{aligned}$

estimated from published literature. AEs involving surgical atrial septal defect (ASD) and patent foramen ovale (PFO) closure were likewise obtained from the Society of Thoracic Surgery (STS) Congenital Cardiac Surgery Database, such that a comparative analysis could be performed.

\section{MATERIALS AND METHODS}

The Manufacturer and User Facility Device Experience (MAUDE) database was accessed via the USFDA main Web page. ${ }^{1}$ A query was performed using the brand name "Amplatzer"' to select for AEs involving all Amplatzer devices, and only the results for ASD and PFO closures were included in this analysis. The first such reported AE was received by the USFDA on January 24, 2002, and the search was arbitrarily concluded on June 30, 2007 , for a total of a 5.5-year collection period. Events were broadly classified into categories (Table 1). If multiple AEs occurred within a single patient narrative, the event that dominated the clinical presentation and course of the patient was used for classification purposes. Device "embolization" was defined by the movement of a device to a location other than the atrial septum, differentiating it from device "malposition," an unacceptable position within the atrial septum. Cardiac perforation/erosion/rupture (PER) was defined as any narrative where perforation, device erosion, or rupture of a cardiac structure occurred or was thought to have occurred. This is differentiated from the category of "pericardial effusion," which would be a serous effusion or one in which a perforation or erosion was not suspected. Infection refers to cases in which the device was thought to be the infectious source, and the thromboembolitic event category included all stroke, transient ischemic attack, and device thrombus events.

All data regarding the manner in which complications were addressed (catheter intervention, operative management, or both) and the final outcome (mortality) were included in the analysis when sufficient information was provided in the reported narrative. Any patient with death as the outcome of the AE was listed as a device mortality, whereas all patients undergoing operation in the management of the $\mathrm{AE}$ were counted as "surgical rescue." To calculate the relative frequency of events, a request was made to AGA Medical for estimates of implants over the study period. This request was subsequently denied via electronic mail correspondence. Thus, a previously published device estimate calculation was used to generate a denominator and allow comparison with STS data.

The STS Congenital Cardiac Surgery Database was likewise quarried for the results of surgical closure of defects at the atrial septum during a similar time frame (beginning January of 2002 with data available through December 2006). Patients with primary closure of PFO, primary ASD closure, and patch closure of ASD as the primary qualifying index operation were included in the analysis, whereas patients with other defects addressed at the time of the index operation were excluded secondary to complexity mismatch with device closure candidates. Outcomes were requested and obtained for discharge mortality, postoperative length of stay, and a complete list of any and all complications. From the complication tally, any
TABLE 1. Major adverse event categories for patients reported to the US Food and Drug Administration between January 1, 2002, and June 30, 2007

\begin{tabular}{lcc}
\hline \multicolumn{1}{c}{ Adverse event } & $\begin{array}{c}\text { No. of reported } \\
\text { events }\end{array}$ & $\begin{array}{c}\text { Percentage of } \\
\text { reported events }\end{array}$ \\
\hline Device embolization & 114 & $51 \%$ \\
Cardiac PERs & 51 & $23 \%$ \\
Thromboembolitic & 11 & $5 \%$ \\
$\quad$ complication & & \\
Residual/recurrent defect & 9 & $4 \%$ \\
Device infection & 5 & $2 \%$ \\
\hline
\end{tabular}

PER, Perforation/erosion/rupture.

patient undergoing an unplanned reoperation of any kind was counted in the "surgical reoperation" group. The overall mortality rate of surgical versus device closure was compared, as was the need for surgical rescue compared with surgical reoperation. The rate of death per $\mathrm{AE}$ and need for operation per $\mathrm{AE}$ were also compared for device versus surgical closure.

Because the MAUDE database narratives are widely and freely available to the public on the World Wide Web and no patient identification variables are included, there was no requirement for institutional review board permission. Likewise, no such institutional permission is needed for the use of STS data; permission was requested and granted from the STS database committee. All data were coded using an Excel spreadsheet (Microsoft Corp, Redmond, WA), and all percentages all reported with the accompanying raw numeric data in the form of a fraction. Inferential statistics were performed as 2-tailed chi-square analysis ${ }^{2}$ for categoric data.

\section{RESULTS}

Manufacturer and User Facility Device Experience Database Adverse Events: Embolization and Perforation/Erosion/Rupture

AE reports totaling 274 involving any type of Amplatzer device were received over a 5.5-year period; closure of

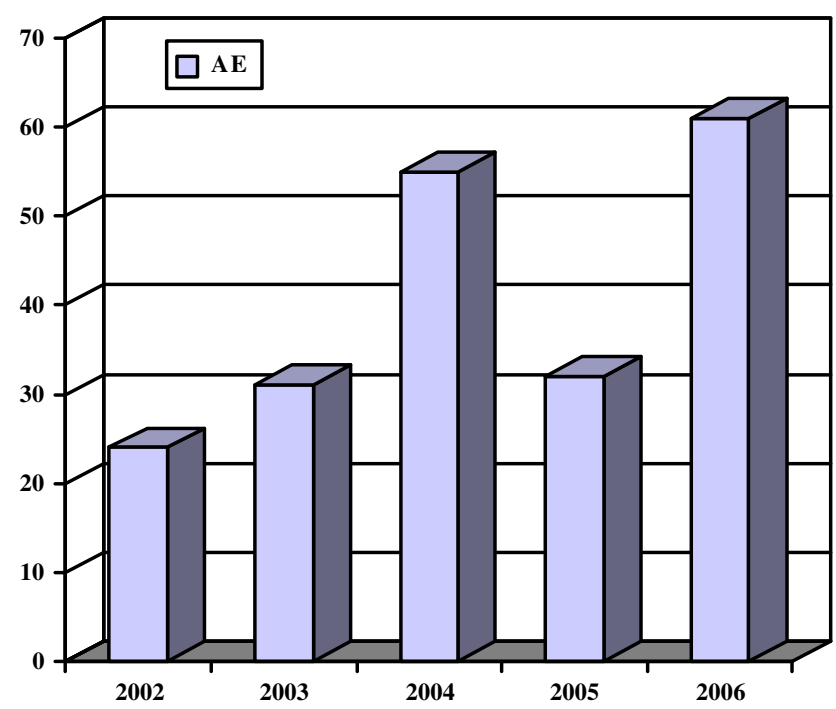

FIGURE 1. Histogram demonstrating the number of AEs involving the Amplatzer (AGA Medical Corporation, Plymouth, MN) septal occluder reported to the USFDA between January 2002 and December 2006. AE, Adverse event. 
TABLE 2. Failing component listed for adverse events reported to the US Food and Drug Administration between January 1, 2002, and June 30, 2007

\begin{tabular}{lcc}
\hline Failing component & $\begin{array}{c}\text { No. of reported } \\
\text { events }\end{array}$ & $\begin{array}{c}\text { Percentage of } \\
\text { reported events }\end{array}$ \\
\hline ASD occluder device & 197 & $88.3 \%$ \\
PFO occluder device & 16 & $7.2 \%$ \\
Delivery catheter & 10 & $4.5 \%$ \\
Sizing balloon & 6 & $2.7 \%$ \\
Guidewire & 1 & $0.5 \%$ \\
Unknown & 2 & $0.9 \%$ \\
\hline
\end{tabular}

$A S D$, Atrial septal defect; $P F O$, patent foramen ovale.

the atrial septum was involved in 232 reports $(84.7 \%)$ (Figure 1). Reliable morphologic data on the location within the atrial septum was unavailable, and specific patient demographics and identifiers such as age, weight, body surface area were likewise not found in the online reports. The specific Amplatzer system elements identified as the failing component in the $232 \mathrm{AE}$ narratives are listed in Table 2. Careful review of each independent event narrative revealed that multiple entries were sometimes found when multiple devices were used for the same patient. Controlling for these duplications resulted in 223 individual patients having AEs.

Death is listed as the outcome for 17 of 223 patients (7.6\% mortality per AE, Table 3). Cardiac PER was the most frequent $\mathrm{AE}$ type resulting in mortality (10/17, $58.8 \%$ ). One woman who survived perforation lost her pregnancy, although this was not counted as mortality. To provide a denominator for analysis, we relied on a published precedent for implant estimate calculation used by Delaney and colleagues, ${ }^{3}$ which was derived from published esti-

TABLE 3. Mortality among adverse events in 223 patients reported to the US Food and Drug Administration between January 1, 2002, and June 30, 2007

\begin{tabular}{ccl}
\hline Number & $\begin{array}{c}\text { Failing component } \\
\text { catalog number }\end{array}$ & Adverse event type \\
\hline 1 & 9 -ASD-022 & Cardiac PER \\
2 & $9-A S D-000$ & Cardiac PER \\
3 & $9-A S D-020$ & Cardiac PER \\
4 & $9-A S D-026$ & Cardiac PER \\
5 & $9-A S D-026$ & Cardiac PER \\
6 & $9-A S D-019$ & Embolization \\
7 & 0-ASD-017 & Thromboembolitic event \\
8 & $9-A S D-024$ & Embolization \\
9 & $9-A S D-022$ & Sudden death \\
10 & $9-$ PFO-HDE-025 & Myocardial infarction \\
11 & $9-A S D-008$ & Respiratory failure \\
12 & $9-P F O-H A D-025$ & Cardiac PER \\
13 & $9-A S D-026$ & Cardiac PER \\
14 & $9-A S D-026$ & Cardiac PER \\
15 & $9-A S D-036$ & Cardiac PER \\
16 & $9-A S D-026$ & Cardiac PER \\
17 & $9-D E L-12 F-45 / 80$ & Air embolization \\
\hline
\end{tabular}

$P E R$, Perforation, erosion, rupture.

TABLE 4. Location of embolized devices among 114 patients reported to the US Food and Drug Administration between January 1, 2002, and June 30, 2007

\begin{tabular}{lcc}
\hline \multicolumn{1}{c}{ Location } & $\begin{array}{c}\text { No. of reported } \\
\text { events }\end{array}$ & $\begin{array}{c}\text { Percentage of } \\
\text { reported events }\end{array}$ \\
\hline Right atrium & 2 & $1.8 \%$ \\
Right ventricle & 19 & $16.7 \%$ \\
Pulmonary artery & 18 & $15.8 \%$ \\
Left atrium & 28 & $24.6 \%$ \\
Left ventricle & 12 & $10.5 \%$ \\
Aorta & 21 & $18.4 \%$ \\
Unknown & 14 & $12.3 \%$ \\
\hline
\end{tabular}

mates by a panel of physicians who were previously chosen by AGA Medical to perform complication analysis and who appear to be financially linked to the company. ${ }^{4}$ According to these data, approximately 10,000 implants are estimated over a 3-year period from 2002 to 2004. Extrapolation of this rate over a 5.5-year period starting in 2002 gives 18,333 implants and an overall mortality of 17 of 18.333 $(0.093 \%)$.

Embolization of Amplatzer occluder devices was the most prevalent AE (114/223 patients, 51.1\%), giving a national embolization rate of 114 of $18,333(0.62 \%)$. A 2004 survey of AGA proctors determined the rate of embolization to be 21 of 3824 implants $(0.55 \%)$, not significantly different from our data $(P=.599) .{ }^{5}$ There were 2 deaths, giving a mortality rate per embolization of $1.8 \%$. Table 4 lists the sites and relative frequencies of embolization, demonstrating the most frequent embolization to the left side of the heart. In 12 of the 114 cases $(10.5 \%)$, a secondary arrhythmia occurred with embolization and was often the "warning sign" of an AE, triggering further workup (Table 5). Eighty-eight patients with embolization $(77.2 \%)$ required operation, whereas successful transcatheter management was possible in 19 patients $(16.7 \%)$. Management is not known for 5 patients $(4.4 \%)$, and no action was taken in 2 patients $(1.8 \%)$.

TABLE 5. Arrhythmia and device location among 114 patients with device embolization reported to the US Food and Drug Administration between January 1, 2002, and June 30, 2007

\begin{tabular}{rll}
\hline No. & Rhythm disturbance (from narrative) & Device location \\
\hline 1 & Nonsustained VT & Left ventricle \\
2 & Atrial flutter & Unknown \\
3 & "Significant ectopy", & Right ventricle \\
4 & PVCs & Right ventricle \\
5 & PVCs & Right ventricle \\
6 & PVCs & Right ventricle \\
7 & Atrial fibrillation, complete heart block & Pulmonary artery \\
8 & "Transient arrhythmia" & Left atrium \\
9 & Bradycardia (with hypotension) & Aorta \\
10 & PVCs & Right ventricle \\
11 & "Extreme rhythm changes" & Right ventricle \\
12 & VT & Right ventricle \\
\hline$V T$, Ventricular tachycardia; $P V C$, premature ventricular contraction.
\end{tabular}


TABLE 6. Timing of 51 cardiac perforations, erosions, or ruptures as reported to the US Food and Drug Administration between January 1, 2002, and June 30, 2007

\begin{tabular}{lcc}
\hline Timing of event & $\begin{array}{c}\text { No. of reported } \\
\text { events }\end{array}$ & $\begin{array}{c}\text { Percentage of } \\
\text { reported events }\end{array}$ \\
\hline During implant & 4 & $7.8 \%$ \\
Within 24 h & 16 & $31.4 \%$ \\
Within 1 mo & 11 & $21.6 \%$ \\
1-6 mo & 8 & $15.7 \%$ \\
6 mo to 1 y & 2 & $3.9 \%$ \\
> y & 3 & $5.9 \%$ \\
Unknown & 7 & $13.7 \%$ \\
\hline PER, Perforation, erosion, or rupture. &
\end{tabular}

Cardiac PER was the second most commonly reported AE $(51 / 223,22.9 \%)$. Mortality for this complication was 10 of 51 patients $(19.6 \%)$, with 1 survivor losing her pregnancy and at least 2 survivors described as having serious neurologic morbidity. By similarly applying the previous estimates, the national PER rate is 51 of $18,333(0.28 \%)$. A 2004 publication by investigators affiliated with AGA Medical determined the PER rate to be 9 in the known 9000 US implants, giving a rate of $0.1 \%$, which is significantly lower than in our findings $(P=.0003){ }^{4}$ Timing of the AE is listed in Table 6; only 4 events occurred at implant, and whereas most were clustered in the first 6 months, erosions and ruptures are still being reported as late as 3 years after deployment. Table 7 lists the confirmed or suspected locations of cardiac PER; a location is specified in 40 patients and not specified in 11 patients.

Some combination of atrium and aorta was found in 18 patients $(35.3 \%, 18 / 51)$, whereas the atria alone were involved in 13 patients $(25.5 \%, 13 / 51)$. Both cases involving the ascending aorta and 2 of the 3 left atrial appendage perforations were confirmed at surgery or autopsy. The other left atrial appendage perforation was suspected by the implanting physician after frank hemopericardium occurred within "a few hours" of the procedure. One patient died 4 hours after implant and was found to have a $1.5-\mathrm{mm}$ right upper pulmonary vein perforation at autopsy. A device erosion through the atrial septum resulted in a new ASD that was confirmed at catheterization and successfully treated with a new device. Hemoptysis secondary to what the implanting physician thought to be a pulmonary vein perforation developed in 1 patient; the procedure was immediately aborted, and this was successfully managed nonoperatively. Likewise, an implanting physician suspected perforation of the "left atrium or pulmonary vein", on review of a case of frank hemopericardium occurring 2.5 hours after the implant; the drainage slowed down, and successful nonoperative management was used.

In the 11 cases of PER where the location is not specified, 3 cases were confirmed by successful surgical exploration, but the location is unlisted in the narrative. An additional
TABLE 7. Confirmed or suspected locations of 51 cardiac perforation, erosion, or rupture events, as indicated in the reports to the US Food and Drug Administration between January 1, 2002, and June 30, 2007

\begin{tabular}{lcc}
\hline \multicolumn{1}{c}{ Timing } & $\begin{array}{c}\text { No. of reported } \\
\text { events }\end{array}$ & $\begin{array}{c}\text { Percentage of } \\
\text { reported events }\end{array}$ \\
\hline Atrium and aorta & 18 & $35.3 \%$ \\
Left atrium & 8 & \\
Right atrium & 5 & \\
Unlisted atrium & 5 & \\
Atrium alone & 13 & $25.5 \%$ \\
Left atrium & 7 & \\
Right atrium & 2 & \\
Unlisted atrium & 3 & \\
Both atria & 1 & \\
Unlisted & 11 & $21.6 \%$ \\
Left atrial appendage & 3 & $5.9 \%$ \\
Pulmonary vein & 2 & $3.9 \%$ \\
Ascending aorta & 2 & $3.9 \%$ \\
Atrial septum & 1 & $2.0 \%$ \\
"Left atrium or pulmonary vein" & 1 & $2.0 \%$ \\
\hline
\end{tabular}

4 cases were described as sudden grossly bloody pericardial effusions, but the location is unknown because each was successfully treated nonoperatively by pericardial drainage. The timing of 3 of these presentations was within 1 hour $(n=1)$ and within 24 hours $(n=2)$ such that these were most consistent with PER; in the fourth case, presenting at 1 month postimplant, erosion was suspected such that "surgery was scheduled,' but no follow-up details of the operation are given. In 3 cases the location was unknown because each was a death and limited autopsy data are given describing bloody fluid in the pericardium and left side of the chest, making PER the most likely event. In the last unknown case, an infant underwent cardiopulmonary resuscitation several weeks after a device implant and was then found to have a large effusion. It is unclear whether erosion occurred first, mandating cardiopulmonary resuscitation, or erosion occurred during the chest compressions and final outcome is not given.

\section{Surgical Outcome and Comparison Between Databases}

According to MAUDE narratives, 112 patients appear to have been sent directly to the operating room $(112 / 223$, $50 \%$ ), resulting in 2 operative deaths. Forty additional patients $(40 / 223,17.9 \%)$ were sent to the operating room after failed catheter intervention to control the AE, resulting in 2 additional operative deaths. Summation gives 152 of 223 Amplatzer AEs (68.2\%), ultimately requiring operative management and an overall operative mortality for surgical rescue of $2.6 \%(4 / 152)$

STS data revealed that surgical closure of ASD and PFO was performed in 1537 patients; primary closure was performed in 457 patients (35 PFO and 422 ASD); and patch 
TABLE 8. Comparison of overall mortality, need for operation to control adverse event mortality per adverse event, and need for operation per adverse event between device closure and surgical closure groups

\begin{tabular}{lccc}
\hline Benchmark end point & Surgery & Device & $\boldsymbol{P}$ value \\
\hline Overall mortality & $0.13 \%$ & $0.093 \%$ & .649 \\
Need for operation & $0.39 \%$ & $0.83 \%$ & .063 \\
Mortality per AE & $1.2 \%$ & $7.6 \%$ & .004 \\
Operation per AE & $3.6 \%$ & $68.2 \%$ & $<.001$ \\
\hline
\end{tabular}

$A E$, Adverse event. "Need for operation" is defined as reoperation for surgical group and need for surgical rescue for device group.

ASD closure was performed in 1080 patients. Discharge mortality was 2 patients $(0.13 \%)$, and median length of stay was 3.0 days (quartiles 2 and 4 days). Any complication as defined on the STS data harvest worksheets occurred in 167 of 1537 patients (10.9\%). Serious complications, however, were rare; no patient required a pacemaker (no permanent arrhythmia) or any form of dialysis (temporary or permanent), 2 patients had a persistent neurologic finding at discharge $(0.13 \%), 3$ patients had postoperative cardiac arrest $(0.20 \%)$, and 6 patients required unplanned reoperation $(0.39 \%)$. There were no cases of sternal dehiscence, mediastinitis, endocarditis, systemic or pulmonary venous obstruction, phrenic, or recurrent laryngeal nerve injury, and in no case was tracheostomy or mechanical support required.

A comparison of the benchmark events (operative mortality, need for surgery and operative mortality, or need for surgery per $\mathrm{AE}$ ) for device and surgical closure was performed (Table 8$)$. Overall mortality for surgical $(0.13 \%)$ and device closure $(0.093 \%)$ was similar $(P=.649)$. Rescue operation for device closure $(0.83 \%)$ was 2.1 times more likely than reoperation for surgical closure $(0.39 \%)$, closely approaching statistical significance $(P=.063)$. Mortality per AE was higher for device closure than surgical $(7.6 \%$ vs $1.2 \%, P=$ $.004)$. Likewise, the need for surgery to control an AE was higher for device closure $(68.2 \%$ vs $3.6 \%, P<.001)$.

\section{DISCUSSION}

The MAUDE is a USFDA-driven reporting mechanism, the purpose of which is to allow public access and review of AEs involving medical devices. ${ }^{1}$ With the 1976 advent of the Medical Device Amendments to the Federal Food, Drug, and Cosmetic act, the FDA was charged with ensuring the safety and efficacy of such devices. ${ }^{6,7}$ Although premarket requirements are more stringent for class III (highest risk) devices, there are several relevant examples in cardiovascular medicine in which limitations of premarket analysis have been exposed. Two examples from cardiac surgery include the Bjork-Shiley tilting disk prosthesis (Shiley Inc, Irvine, Calif) and the use of St Jude Silzone (St Jude Medical Inc, St Paul, Minn) valve coating. ${ }^{7}$ For these and many other reasons, postmarketing surveillance has become an important focus for the FDA. Voluntary reporting (focusing on the health care professional) has been encouraged in 1973 and was formalized under the "MedWatch program in 1993. Important steps were added in 1984, when Medical Device Reporting regulations enforced mandatory manufacturer reporting, and in 1990, when the Safe Medical Devices Act similarly charged user facilities with the same reporting responsibility. The MAUDE allows rapid access to these reports.

We acknowledge a priory the potentially serious limitations of this analysis and have taken this into consideration regarding the data we have chosen to report. Our experience with MAUDE has confirmed that the events reported are essentially all "sentinel events"; they are the most serious, life-threatening complications (of the device and related hardware) that generated enough concern and exposure that the physicians or user facilities thought that a report was necessary. Procedural-related complications such as access site problems (bleeding, infection, arteriovenous fistula), blood transfusion, contrast allergy, anesthesia, and airway problems and other commonly recognized catheter complications are not captured by such a database. Furthermore, data from the General Accounting Office report that less than $0.5 \%$ of all medical device AEs actually end up reported to the FDA, a serious source of potential error in using these data as a national estimate. ${ }^{8}$ The STS database only includes approximately half of the congenital centers in the country and on a voluntary basis such that extrapolation of results to all centers provides a source of potential error. The STS database does not account for perception of pain and other end points that would certainly confirm clear advantages to some aspects of catheter procedures. Perhaps the most serious deficiency of the STS database, however, is that the data are not longitudinal.

It is for these reasons that we choose to analyze death and need for operation (surgical rescue vs surgical reoperation) as benchmark end points; both are definitive categoric ("yes or no") outcomes of significant interest to clinicians and patients. We believe that the issue of requiring an operation to control an $\mathrm{AE}$ is of particular interest given our finding that the mortality rate of surgical rescue is 20 -fold higher than for elective repair. Thus, the argument that " the patient is only getting the same operation they would have gotten anyway" does not apply to operations for device complications. Attempts to group certain possible complications from a procedure as "serious" or "potentially serious" are fraught with numerous pitfalls and problems such that the subject has itself become an independent science; it is well beyond the scope of this article to breech this topic, and so we make no such comparisons.

\section{Results of the Manufacturer and User Facility Device Experience Database and Society of Thoracic Surgery}

Comparing the embolization, PER, and thromboembolitic event rates from the MAUDE database with the published 
literature, we find that the current rate of embolization is the same as was found in a 2004 survey of AGA proctors, ${ }^{5}$ whereas the PER rate is 3 times that reported in 2004 by AGA investigators. ${ }^{4}$ Embolized devices often require operative intervention, and there is a risk of damage to cardiac structures with catheter removal. Comparison of thromboembolitic event rates with other publications reveals that it may be a bigger problem than is currently believed. Only 1 such complication was found in 3 major studies (including 2 specifically aimed at detecting thrombosis rates), ${ }^{9-11}$ and a report in 2006 claims to be first to report stroke from an Amplatzer device. ${ }^{12}$

Comparison with other publications also confirms a lower published rate of death and serious complications than or findings indicate. ${ }^{13-16}$ From 2003 to 2006, 5 case reports of device erosion and perforation are found in the literature, and these seem to be accounted for in the MAUDE database. ${ }^{17-21}$ Twice before, investigators have published results of the reported PER events from the MAUDE database, ${ }^{3,22}$ and there continues to be debate over the cause of this complication. The findings of Divekar and colleagues ${ }^{22}$ highlight that larger devices $(>25 \mathrm{~mm})$ do not seem to be overrepresented in the known events and that many patients with oversized devices do not experience perforation. We conclude that this seems to be a more frequently encountered complication with a high mortality but make no conclusions about cause.

\section{CONCLUSIONS}

The overall mortality for device and surgical closure of the atrial septum seems equivalent, and the need for subsequent operation (surgical rescue) may be more common in patients undergoing device closure than reoperation is in patients undergoing surgical closure. Complications from device closure tend to be serious and most often require urgent or emergency operative management, whereas the mortality for surgical management of a device complication appears higher than that of elective ASD closure. Further information is required in the form of postmarketing surveillance, such as a mandatory user registry with periodic enduser notification.

\section{References}

1. U.S. Food and Drug Administration Web site. Available at: http://www.fda.gov/ default.htm.

2. GraphPad Software Web site. Available at: www.graphpad.com.

3. Delaney JW, Li JS, Rhodes JF. Major complications associated with transcatheter atrial septal occluder implantation: a review of the medical literature and the MAUDE database. Congenit Heart Dis. 2007;2:256-64.

4. Amin Z, Hijazi ZM, Bass JL, Cheatham JP, Hellenbrand WE, Kleinman CS. Erosion of Amplatzer septal occluder device after closure of secundum atrial septal defects: review of registry of complications and recommendations to minimize future risk. Catheter Cardiovasc Interv. 2004;63:496-502.

5. Levi DS, Moore JW. Embolization and retrieval of the Amplatzer septal occluder. Catheter Cardiovasc Interv. 2004;61:543-7.

6. O'Shea JC, Kramer JM, Califf RM, Peterson ED. Sharing a commitment to improve cardiovascular devices. Part I: Identifying holes in the safety net. Am Heart J. 2004; 147:977-84.
7. Peterson ED, Hirshfeld JW, Ferguson TB, Kramer JM, Califf RM, Kessler LG. Sharing a commitment to improve cardiovascular devices. Part II: Sealing holes in the safety net. Am Heart J. 2004;147:985-90.

8. Gross TP, Kessler LG. Medical device vigilance at FDA. Stud Health Technol Inform. 1996;28:17-24.

9. Chessa M, Carminati M, Butera G, et al. Early and late complications associated with transcatheter occlusion of secundum atrial septal defect. J Am Coll Cardiol. 2002;39:1061-5

10. Krumsdorf U, Ostermayer S, Billinger, et al. Incidence and clinical course of thrombus formation on atrial septal defect and patent foramen ovale closure devices in 1,000 consecutive patients. J Am Coll Cardiol. 2004;43:302-9.

11. Anazai H, Child J, Natterson, et al. Incidence of thrombus formation on the CardioSEAL and the Amplatzer interatrial closure devices. Am J Cardiol. 2004;93: 426-31.

12. Raghu A, Kawalsky D, Feldman M. Embolitic stroke due to a left atrial thrombus two years after placement of an atrial septal defect closure device. Am J Cardiol. 2006;98:1294-6

13. Butera G, Carminati M, Chessa M, et al. CardioSEAL/STARflex versus Amplatzer devices for percutaneous closure of small to moderate (up to $18 \mathrm{~mm}$ ) atrial septal defects. Am Heart J. 2004;148:507-10.

14. Wang JK, Tsai SK, Wu MH, Lin MT, Lue HC. Sort-and intermediate-term results of transcatheter closure of atrial septal defect with the Amplatzer septal occluder. Am Heart J. 2004;148:511-7.

15. Hong TE, Thaler D, Brorson J, Heitschmidt M, Hijazi ZM. Transcatheter closure of patent foramen ovale associated with paradoxical embolism using the Amplatzer PFO occluder: initial and intermediate-term results of the U.S Multicenter Clinical Trial. Catheter Cardiovasc Interv. 2003;60:524-8.

16. Du ZD, Hijazi ZM, Kleinman CS, Silverman NH, Larntz K. Comparison between Transcather and surgical closure of secundum atrial septal defect in children and adults. J Am Coll Cardiol. 2002;1836-44.

17. Grayburn PA, Schwartz B, Anwar A, Hebeler RF. Migration of an Amplatzer septal occluder device for closure of atrial septal defect into the ascending aorta with formation of an aorta-to-right-atrial fistula. Am J Cardiol. 2005;96:1607-9.

18. Preventza O, Sampath-Kumar S, Wasnick J, Gold JP. Later cardiac perforation following transcatheter atrial septal defect closure. Ann Thorac Surg. 2004;77: 1435-7.

19. Maimon MS, Ratnapalan S, Do A, Kirsh JA, Wilson GJ, Benson LN. Cardiac Perforation 6 weeks after percutaneous atrial septal defect repair using an Amplatzer septal occluder. Pediatrics. 2006;118:e1572-5.

20. Chun DS, Turrentine MW, Moustapha A, Hoyer MH. Development of aorta-toright atrial fistula following closure of secundum atrial septal defect using the Amplatzer septal occluder. Catheter Cardiovasc Interv. 2003;58:246-51.

21. Cecconi M, Quarti A, Bianchini, et al. Later cardiac perforation after transcatheter closure of patent foramen ovale. Ann Thorac Surg. 2006;81:e29-30.

22. Divekar A, Gaamangwe T, Shaikh N, Raabe M, Ducas J. Cardiac perforation after device closure of atrial septal defects with Amplatzer septal occluder. J Am Coll Cardiol. 2005;45:1213-8.

\section{Discussion}

Dr Carl L. Backer (Chicago, Ill). I want to congratulate Dr DiBardino and colleagues at Children's Hospital Boston for their very clever idea of mining the MAUDE database to determine the incidence of adverse events involving the Amplatzer septal occluder device. I first became aware of this database at the AATS in Toronto in 2004 when Richard Jonas debated Andrew Reddington about this very topic. A brief look at that MAUDE database is quite an eye-opener.

This is a very timely presentation and an important analysis. The issue of device closure was the first paper at the STS in the Plenary Session this year. In that paper, Dr Tara Karamlou also mined a database, the Nationwide Inpatient Sample and ICD-9 procedure and diagnosis codes. She discovered an increased incidence of ASD closure mostly due to a sudden and dramatic rise in percutaneous closure beginning in the year 2001.

The comparison of the MAUDE database to the STS database clearly demonstrates the importance of our own congenital 
database. When I debated this topic at the ACC 3 years ago, the cardiologists complained that there is no MAUDE database for surgeons. The STS database is our answer to that issue.

I have three questions for you, and they relate to your numerator and your denominator.

My first question relates to the numerator in your analysis. There were 223 adverse events and 17 deaths related to the Amplatzer device. At the AATS meeting in 2006, when we had a similar discussion, I asked this audience how many people had taken Amplatzer devices out of various parts of the body; nearly everyone in the room raised their hand. Is it possible that the MAUDE database might only be capturing the tip of the iceberg, and how confident are you in your numerator?

Dr DiBardino. Thank you Dr Backer. That's a tricky question to answer. I presented this data to the interventional cardiologists in Boston before I left and it's their sense that this is the tip of the iceberg. There are folks who place these devices who don't know about the MAUDE database. And that makes me very suspicious that our numerator is, in fact, grossly under-reported.

There was an interesting study published by the United States General Accounting Office that stated that $0.5 \%$ of all device-related complications ever make it to the FDA-0.5\%. And that also makes me very wary of this numerator. I think that this is the tip of the iceberg.

Dr Backer. My second question relates to the denominator. The analysis of the predicted complication rate of the Amplatzer device hinges on this number. You noted in your manuscript that a request of AGA Medical was made for an estimate of implants over the time of the study period and that this request was denied. You derived an estimate of 18,333 implants, although the paper you quoted was from 2004. This makes the calculated mortality of the Amplatzer device 1 in 1,000. How comfortable are you with the denominator that you have given us?

Dr DiBardino. Well, the 2 papers that I mentioned (from 2004 and 2007) were both papers that used implants estimates based on AGA medical data and the 2004 paper was published by folks financially tied to AGA medical. So the number 18,333 comes from an estimation that was made of implants over about a 2and-a-half year period; we simply converted that estimate into "number of implants per month", and multiplied it by 66 months, or 5.5 years. I think it's the best we can do. I can't speak to its accuracy because I cannot externally validate it, but I do submit that it is an honest effort and the best we can do.

Dr Backer. And what about the company not responding to your requests?

Dr DiBardino. Well, yes, it was actually interesting. I called the Boston AGA Medical representative (who services Children's Hospital Boston) and asked for the actual implant numbers. They looked into it, and I received an electronic mail correspondence subsequently that said that that information would not be available for me. I just can't get it.

Dr Backer. All right. My final question relates to the incidence of complications in the MAUDE database over time. It was a little disturbing to see that slide that showed that actually the number of reports are increasing per year. This could possibly be related to an increase in the total number of devices implanted or that there is not a positive learning curve that we would hope would happen. When we discussed this in 2006, Dr del Nido noted that the interventional cardiologists are now looking at things like the size of the aortic rim, not oversizing the device, more careful follow-up, and that this would, indeed, actually reduce the incidence of these complications. What's your feeling, looking at this database, whether the incidence of these complications is going up or down over time?

Dr DiBardino. Well, the histogram that I showed is not very useful because it, of course, does not answer the question about whether the increase in reported events is simply that people are reporting them more often or are they being implanted more often such that the frequency of complications cannot be ascertained. The cardiology literature does comment on the fact that, after the device was first approved for general use, there was perceived to be a rise in the complication rate and this has been ascribed to the unfamiliarity of new cardiologists to that device. Beyond around 2004-2005, we sort of lose track of that in the literature. I really don't have enough information to truly accurately know what the trend is in complication rate.

Dr Jeffrey P. Jacobs (St. Petersburg, Fla). First, I would like to congratulate you for doing a great job and making an outstanding presentation. It really makes me proud to see our database, the STS Congenital Heart Surgery Database, mature to the point that it can be used for a study like this one. I think you did a great job with this study and presented it quite well.

I think one could criticize the data from the STS database by saying that it stops at hospital discharge, and we do not know what happens after hospital discharge. This criticism underscores the importance of what we are trying to accomplish in the STS database by incorporating HIPAA Compliant Unique Patient, Surgeon, and Hospital Identifier Fields into the STS Database, and creating a framework where our database can be used as a tool for longitudinal follow-up. The STS Adult Cardiac Database has incorporated these identifier fields as of January 1, 2008. These fields will be incorporated into the STS Thoracic Database on January 1, 2009, and into the STS Congenital Heart Surgery Database on January 1, 2010. I think that this accomplishment is going to mature our STS database.

My question is: How would you recommend maturing the way that we follow these devices, and the device databases, based on what you have learned from this study?

Dr DiBardino. Thank you, Dr Jacobs. In my time as a junior resident in general surgery in Dr Chuck Fraser's research lab, I became interested in databases and outcomes analysis and hope to make that the backbone of my own academic career as I progress.

I think the answer to your question is that if you look at the history of the FDA in cardiovascular surgery, there are numerous examples (the Bjork-Shiley prosthesis, the Silzone coating that was transiently used on St. Jude valves) of where postmarketing surveillance has become important. Even changed the way products are handled, what their recommendations are for their placement and, in some cases, products being eliminated from the market. I think what we're not going to have is a head-to-head trial. It's just not going to happen. I think an easy solution would be simply creating a registry, an implant registry, with periodic end-user notification. That has been done with LVADs; it is easy and effective and it would give us real answers about what the numerators and denominators are.

Dr Shunji Sano (Okayama City, Japan). Just over one year, we studied the Amplatzer ASD closure. In the last year, our cardiologists 
have done 94 Amplatzer ASD closures and defend the first-year closure on 10 patients. And we have no host mortality and no surgical rescue, one temporary episode of thromboembolism. So the result is completely different from yours. I think maybe the difference is the indication. If you have wide range of indications, you have more complications.

The question is: Do you have surgeons involved in the indication of Amplatzer ASD closure and surgical closure? Because we, in our unit, the surgeon is completely involved in the indication of the technique, 2 techniques, and our young surgical fellow is also involved in this procedure.

Dr DiBardino. Well, I think what you're describing is very common when you examine the results from a single center that has excellent physicians who are doing procedures that they are very experienced with. And if you look at single-center reporting from the United States, you'll find the results that you've just described: No mortality, no erosions, no embolizations. But when you apply a product to the general audience and you allow people who are less familiar with it, then, to start using it, there is going to be a learning curve. And I think that's part of what we're seeing in this analysis.

In Boston, the surgeons are not involved in the decision, by and large, to place implants or devices. One thing I will say, however, is that our interventionalists (one of whom is my coauthor on this paper) are gifted and talented but also careful. What I mean to say is that they are very careful about their selection and techniques in terms of using stop-flow technique for balloon sizing, paying careful attention to the amount of retro-aortic rim, and being very careful not to oversize devices. They're probably more careful about it than they are at some other places and there not afraid to send certain patients to the operating room. All of this leads, as it has at your center, to a low complication rate. But I think that it's difficult to extrapolate those results to everywhere, all over, because of the different comfort level and skill level of the physicians who provide care. 